\title{
RESEARCH ON CURVILINEAR MOTION OF AUTOMOBILE WITH THE APPLICATION OF ON-BOARD CAN BUS DATA
}

\author{
Hubert Sar*, Mateusz Brukalski, Krzysztof Rokicki \\ Institute of Vehicles and Construction Machinery Engineering, Warsaw University of Technology, Warsaw, Poland \\ *E-mail of corresponding author: hubert.sar@pw.edu.pl
}

\begin{abstract}
Resume
Modelling of vehicle's motion is one of the solutions applied in the research of automotive safety. There is always a discussion which model should be used for computer simulation. Models with higher number of degrees of freedom require identification of many parameters, which are usually difficult to obtain. So, very often relatively simple flat model of vehicle's motion is applied. It needs only such parameters as mass of a vehicle, location of centre of gravity from front and rear axle, yaw mass moment of inertia and side slip characteristics of the front and rear axle. In this paper the upper mentioned model was applied, considering different side slip characteristics of the front and rear axle. The scenario of vehicle's motion was based on random changes of steering wheel angle during the road test, recording signals from on-board CAN (Controller Area Network) bus of automobile simultaneously, which were further applied in simulation.
\end{abstract}

Available online: https://doi.org/10.26552/com.C.2021.3.B211-B218

\section{Article info}

Received 16 September 2020

Accepted 7 November 2020

Online 15 April 2021

\section{Keywords:}

CAN bus data, vehicle's motion modelling, automotive safety, side slip phenomenon, computer simulation

ISSN 1335-4205 (print version) ISSN 2585-7878 (online version)

\section{Introduction}

Research on automotive safety is conducted in a variety of ways. First, it may be investigation of driver's influence on the level of traffic safety, estimating reaction times on different disturbances generated on the road as mentioned in [1-4]. Moreover, research on vehicles' safety is analysed through the approach to automotive suspension's modelling, vertical vibrations of automobile's body as presented by [5-6], because the contact between tyres and road should be enough to transmit tangential forces resulting both from cornering, driving and braking forces. Vehicle's motion models are very sophisticated, including many interactions and many degrees of freedom, for example [7]. In turn, advanced tyre models are used, where interactions in three directions are included together with bending vibrations inside the tyre's structure [8]. Some papers refer to traffic safety through the analysis of postaccident investigation of traffic incidents as presented by [9]. Because of the vision systems development, they became helpful in researching vehicles' motion as depicted in [10]. Safety of heavy vehicles, for example firefighting automobiles, is discussed in [11], where the braking distance is considered. Very interesting approach can be found in [12], where the road profile estimation and vehicle model investigation are performed through the data from mobile devices. Computer simulation of automobile's motion is regarded as a cheap method of investigating its important properties. Of course, it must be preceded by the road measurements, applying suitable measurement equipment. Furthermore, adequate mathematical model of a vehicle must be applied. If a model is more sophisticated, it requires more parameters for identification. Thus, validation of such a model may be more problematic. Although, one can estimate some parameters of a model, but it should be done with relatively low error. Very often, for the rapid preparation of a simulation, a flat model of a vehicle, as presented in the article, is used. Another important issue are road measurement tests, for which it is necessary to apply adequate measurement equipment like data acquisition system and sensors. In this paper, data coming from the CAN (Controller Area Network) bus of a vehicle through special measurement card, was applied.

\section{Data acquisition system}

To be able to compare the measurement and simulation results, some signals had to be recorded, which also corresponded to the output signals of a model. Additionally, steering wheel angle signal and velocity of a vehicle were input signals of a model, which provided the basis for comparing the measurement results to the simulation results. Only velocity of a vehicle was taken outside the CAN bus. It was collected from simple $10 \mathrm{~Hz}$ 


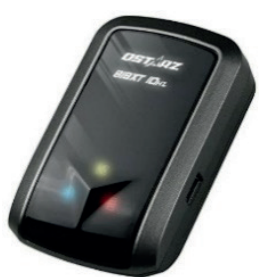

Figure 1 GPS receiver QSTARZ BT-Q818XT 10Hz [13]

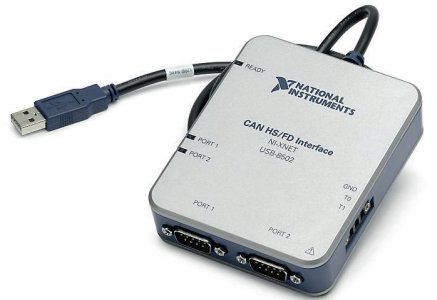

Figure 2 CAN bus data acquisition card [14]

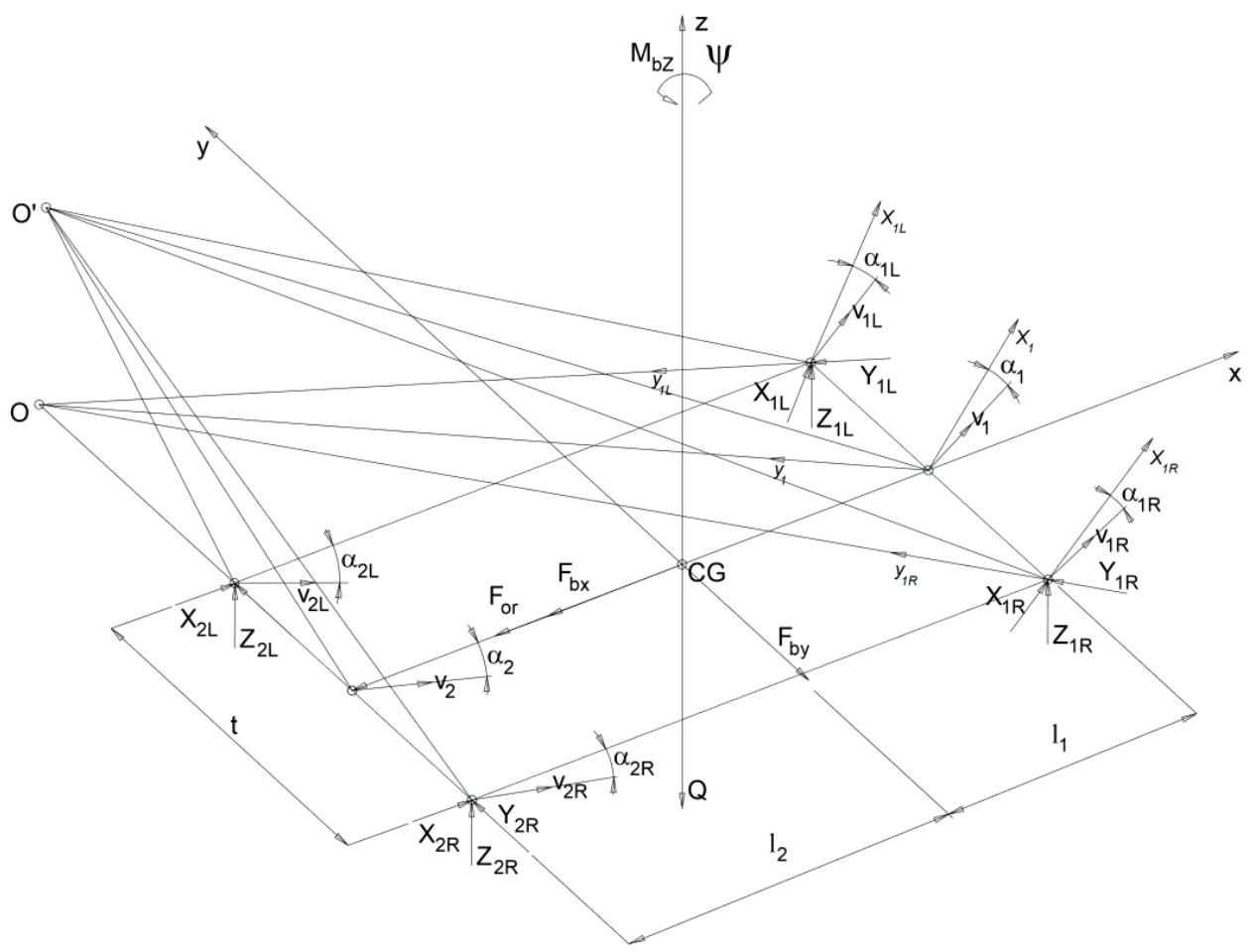

Figure 3 Flat model of automobile for description of curvilinear motion of automobile

GPS (Global Positioning System) receiver (see Figure 1). Other signals, typical for Electronic Stability Program (ESP), like lateral acceleration, yaw rate sensor and steering wheel angle, were recorded from the CAN bus through the special data acquisition measurement card (see Figure 2). It is important to say that this method of measurement is not a substitute for the professional data acquisition systems. The article only shows a new approach to road tests, applying cheaper measurement equipment, without necessity to buy new sensors and mount them inside a vehicle.

\section{Mathematical description of vehicle's curvilinear motion}

As already mentioned in the introduction, simple flat model of a vehicle (depicted in Figure 3) was applied in this paper. It included only a few inertial parameters as mass, its distribution between the front and rear axle, yaw mass moment of inertia. Of course, to perform the simulation, it needed two input signals - steering wheel angle and velocity of a vehicle. Additionally, it required an information about the side slip properties of the front and rear axle. Lateral forces and slip angles of the left and right part of front and rear axle are included separately in equilibrium equations of vehicle's model. The reason for this is that in the future it is planned to extend the model by applying the roll and pitch angle of vehicle body's motion. It will result in the changes of normal reaction forces between the road and a wheel, thus influencing lateral forces connected with side slip phenomenon.

Here are presented descriptions of symbols used in Figure 3 where:

$X_{i}, Y_{i}, Z_{i}$ - (in capitals) reaction forces between left, right part of front or rear axle;

$x, y, z$ - coordinate system connected with a vehicle;

$x_{i}, y_{i}, z_{i}$ - (small letters) local coordinates' system of left, right side of front axle;

$\alpha_{i}$ - side slip angle of left, right side of front or rear axle;

$v_{i}$ - resultant velocity of i-part of a vehicle;

$Q$ - weight of a vehicle;

$O$ - theoretical centre of vehicle's rotation; 


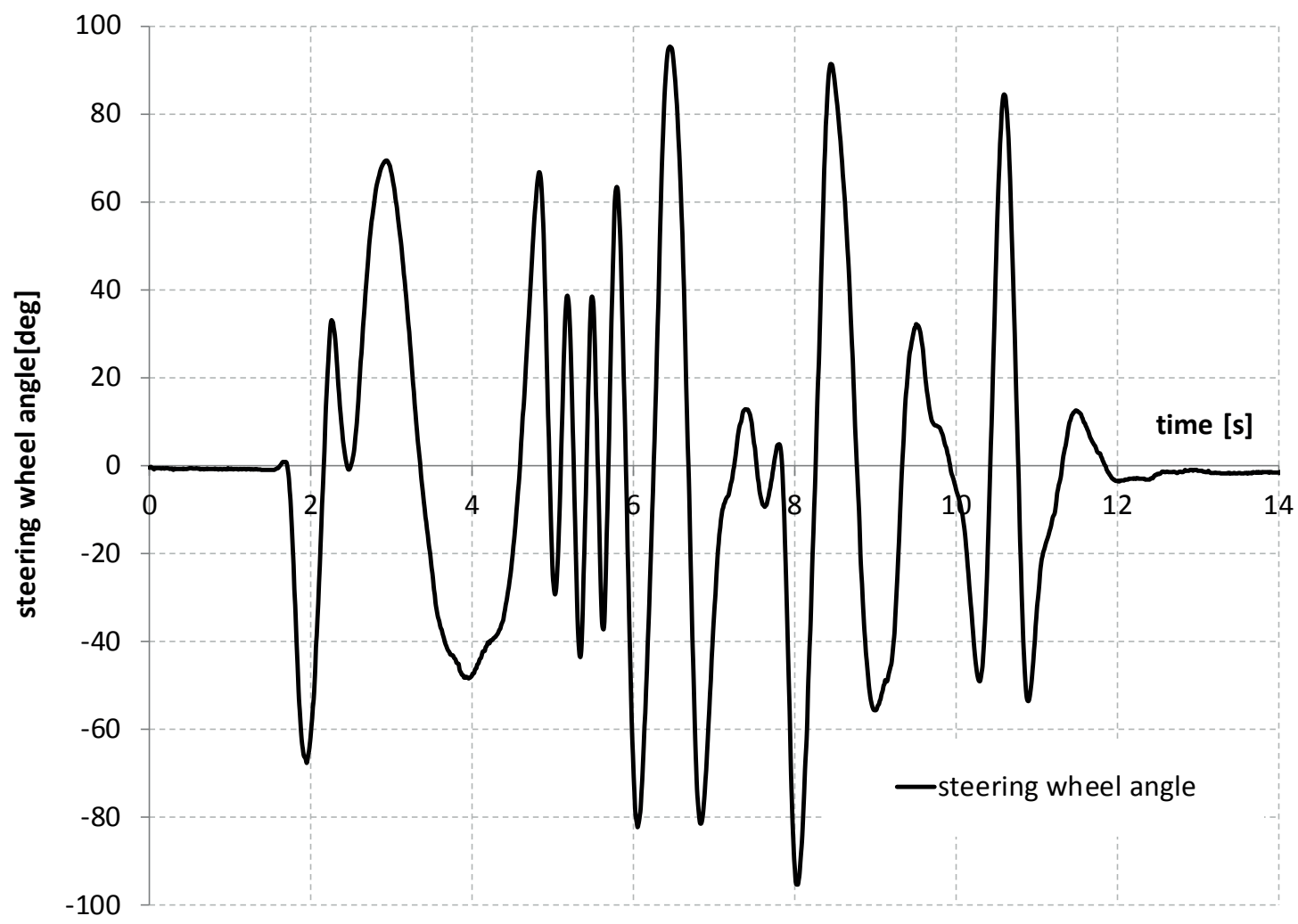

Figure 4 The time course of the steering wheel angle of investigated vehicle

O’ - real centre of vehicle's rotation (including side slip phenomenon);

$C G$ - centre of gravity;

$M_{b z}$ - yaw torque of inertial resistance;

$F_{b y}$ - inertial lateral force;

$\psi$ - yaw angle.

The steady-state condition of vehicle's motion in longitudinal direction, was assumed, as well. So that, forces $F_{b x}$ and $F_{o r}$ were assumed as equal zero.

Equilibrium equations for the model presented in Figure 3 are presented below.

$F_{b y}=X_{1 R} \cdot \sin \delta_{1 R}+X_{1 L} \cdot \sin \delta_{1 L}+Y_{1 R} \cdot \cos \delta_{1 R}+$

$+Y_{1 L} \cdot \cos \delta_{1 L}+Y_{2 R}+Y_{2 L}$,

$m \cdot \dot{x} \cdot \phi+m \cdot \ddot{y}=X_{1 R} \cdot \sin \delta_{1 R}+X_{1 L} \cdot \sin \delta_{1 L}+$

$+Y_{1 R} \cdot \cos \delta_{1 R}+Y_{1 L} \cdot \cos \delta_{1 L}+Y_{2 R}+Y_{2 L}$,

$M_{b z}=X_{1 L} \cdot \cos \delta_{1 L} \cdot \frac{t}{2}-X_{1 L} \cdot \sin \delta_{1 L} \cdot l_{1}-Y_{1 L}$.

$\cdot \cos \delta_{1 L} \cdot l_{1}-Y_{1 L} \cdot \sin \delta_{1 L} \cdot \frac{t}{2}-X_{1 R} \cdot \cos \delta_{1 R} \cdot \frac{t}{2}+$

$-X_{1 R} \cdot \sin \delta_{1 R} \cdot l_{1}-Y_{1 R} \cdot \cos \delta_{1 R} \cdot l_{1}+Y_{1 R} \cdot \sin \delta_{1 R}$

$\cdot \frac{t}{2}+X_{2 L} \cdot \frac{t}{2}+Y_{2 L} \cdot l_{2}-X_{2 R} \cdot \frac{t}{2}+Y_{2 R} \cdot l_{2}$,

$I_{z} \cdot \ddot{\phi}=X_{1 L} \cdot \cos \delta_{1 L} \cdot \frac{t}{2}-X_{1 L} \cdot \sin \delta_{1 L} \cdot l_{1}-Y_{1 L}$

$\cdot \cos \delta_{1 L} \cdot l_{1}-Y_{1 L} \cdot \sin \delta_{1 L} \cdot \frac{t}{2}-X_{1 R} \cdot \cos \delta_{1 R} \cdot \frac{t}{2}+$

$-X_{1 R} \cdot \sin \delta_{1 R} \cdot l_{1}-Y_{1 R} \cdot \cos \delta_{1 R} \cdot l_{1}+Y_{1 R} \cdot \sin \delta_{1 R} \cdot$ $\frac{t}{2}+X_{2 L} \cdot \frac{t}{2}+Y_{2 L} \cdot l_{2}-X_{2 R} \cdot \frac{t}{2}+Y_{2 R} \cdot l_{2}$.
The inertial data of investigated vehicle (Hyundai Veloster 1.6 GDI MY2010) are:

mass of automobile $m=1419 \mathrm{~kg}$, distance between front axle and centre of gravity $l_{1}=1.089 \mathrm{~m}$, distance between rear axle and centre of gravity $l_{2}=1.561 \mathrm{~m}$, average wheel track $t=1.560 \mathrm{~m}$, average steering system ratio $K_{s r}=15.1$.

Moment $I_{z}$ was estimated using the following formula proposed by Heinz Burg [15] in 1982:

$I_{Z}=0.1269 \cdot m \cdot L \cdot l_{12}$.

where: length of automobile $L=4.22 \mathrm{~m}$; 


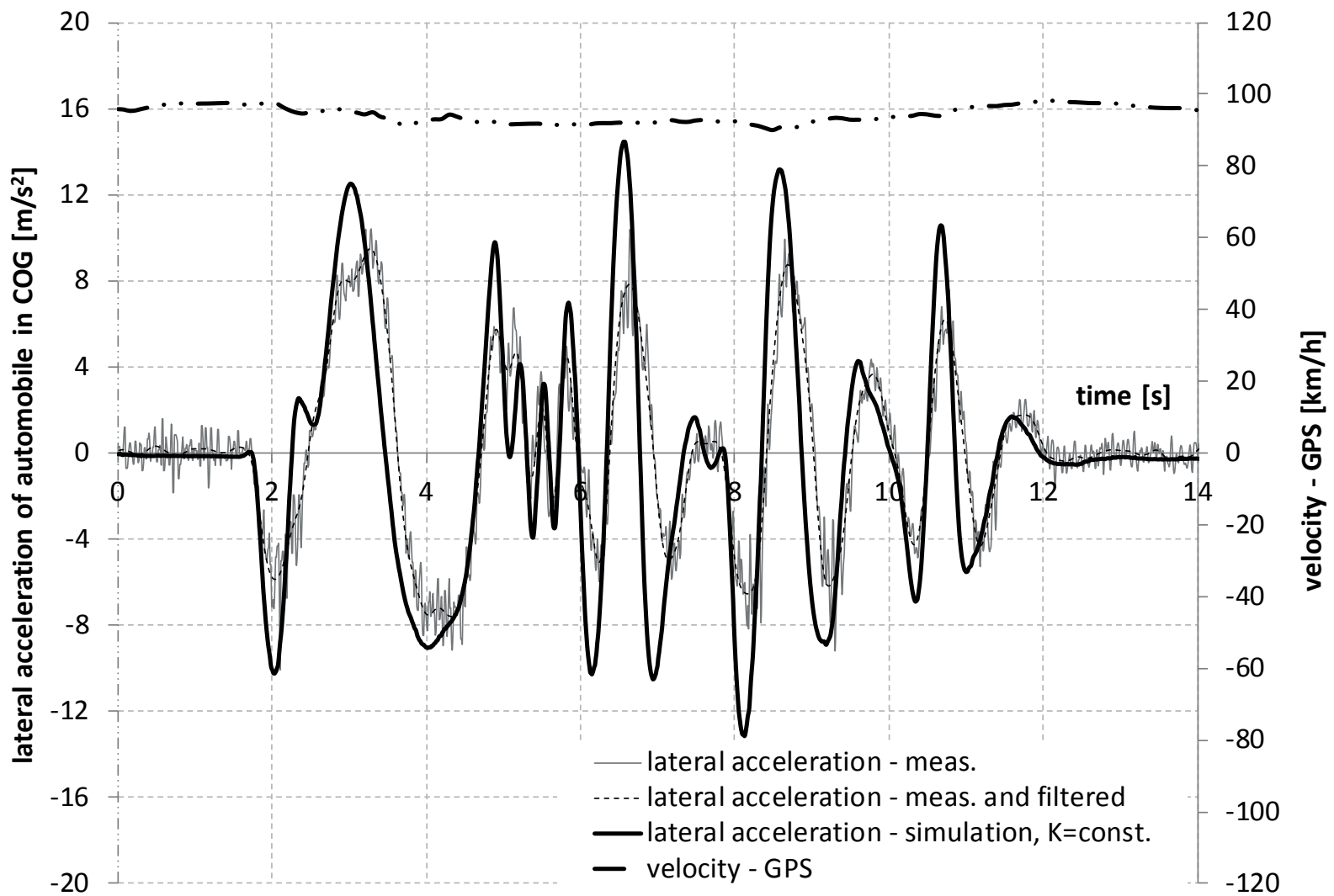

Figure 5 The time course of the lateral acceleration in the centre of mass of investigated vehicle for the linear side slip characteristics

First, the signal, which was common both for measurement and simulation, was the steering wheel angle. Its recorded time course is presented in Figure 4. It does not represent any normative road tests, but very narrow changes of the steering wheel angle. The road test was performed on Biala Podlaska airport.

Computer simulation of vehicle's curvilinear motion was performed for the two different equations describing the dependence between the lateral force and side slip angle of front and rear axle. It was done separately for the left and right side of each axle, because in the future the authors are planning to introduce more degrees of freedom in the model, among others the roll and pitch angle. It will generate changes of normal reaction forces and hence changes of tangential longitudinal and transverse forces between the axle and a road surface. The first Equation (6) is very simplified and includes very popular approach based on application of cornering stiffness coefficient $K$.

$Y=K \cdot \alpha$

where:

$Y$ - lateral reaction force between left or right part of front or rear axle and road surface,

$\alpha$ - side slip angle of the left or right part of front or rear axle and road surface;

$K$ - cornering stiffness coefficient;

$K_{1}=80000 \mathrm{~N} / \mathrm{rad}, K_{2}=105000 \mathrm{~N} / \mathrm{rad}$.
The second type of Equation (7), describing the dependence between the lateral force and side slip angle, is represented by very popular Pacejka's Magic Formula [16] (MF). This non-linear dependence between the lateral force and side slip angle is important regarding higher values of the side slip angles, resulting from higher values of the steering wheel angle. In the case of the analysed test it was nearing \pm 100 degrees.

$$
\begin{aligned}
& Y=-\mu \cdot Z \cdot \sin (C \cdot \arctan (B \cdot \alpha-E \cdot(B \cdot \alpha+ \\
& -\arctan (B \cdot \alpha)))), \\
& \mu=0.9
\end{aligned}
$$

Here are given values of fitting constants for Magic Formula Equation (7), separately for front and rear axle: $C_{1}=1.1, C_{2}=1.1, E_{1}=-15, E_{2}=-15, B_{1}=6.0, B_{2}=10.5$.

Negative values of coefficients $E_{1}$ and $E_{2}$ are resulting from the sense of the lateral reaction forces vectors, acting from the ground on the front and rear axle.

In the presented version of the MF Equation (7), influence of the adhesion coefficient between the axle and a road surface - $\mu$ is included. Looking at Equation (7), lateral force $Y$ is associated with normal reaction force $Z$. In this case the normal reaction forces are assumed as constant, but if the roll and pitch motion was unlocked in the model through adding additional equilibrium equations, that would assure the characteristics of force 


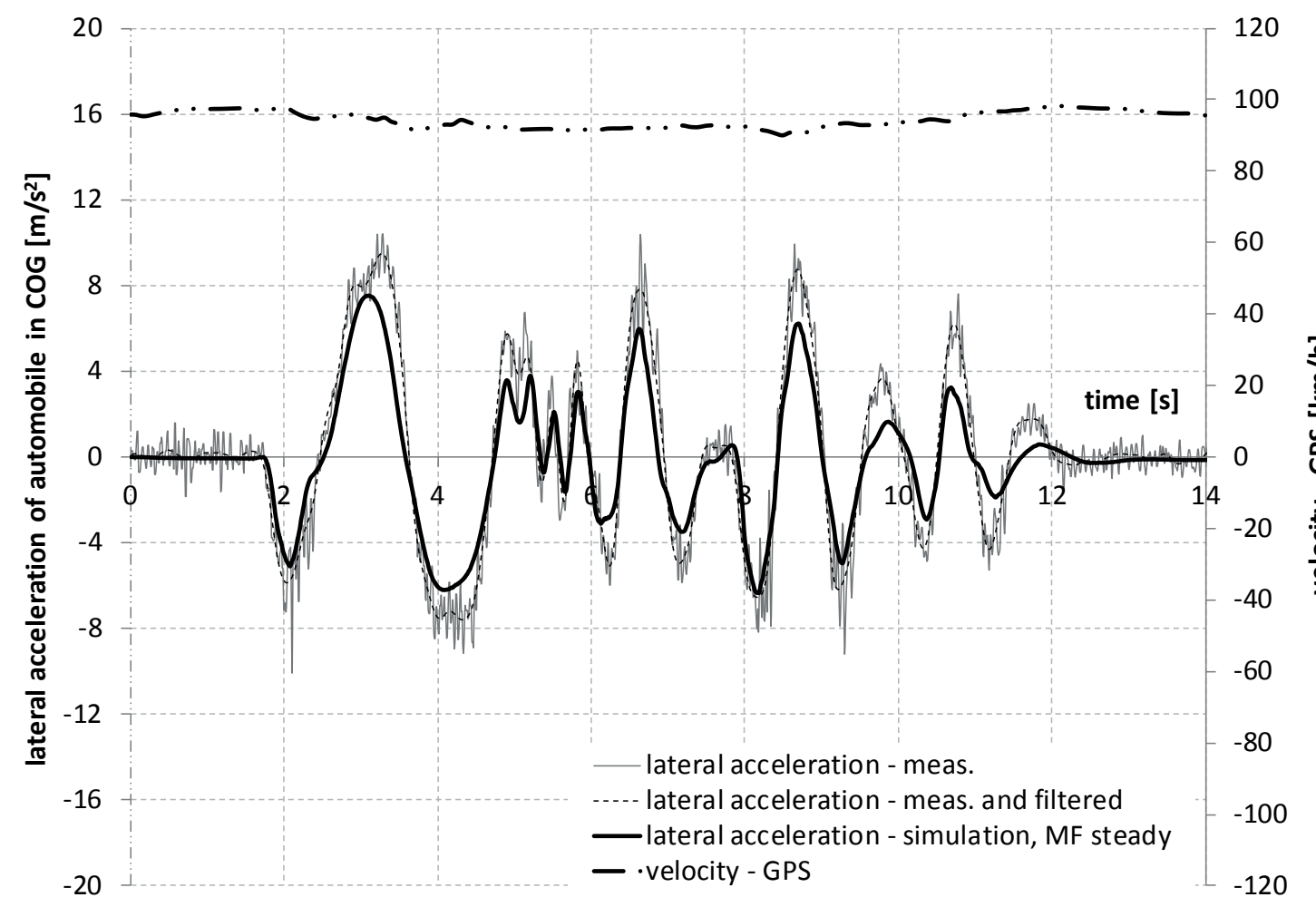

Figure 6 The time course of the lateral acceleration in the centre of mass of investigated vehicle for the side slip characteristics described by Pacejka's Magic Formula

$Y$ as a function of angle $\alpha$, each characteristics for different normal reaction force $Z$.

Figure 5 shows the lateral acceleration of automobile from measurements and from computer simulation with application of the most simplified side slip characteristics (see Equation (6)) - in this case linear. It means that dependence between the lateral force and side slip angle, generated by this force, is described only by the cornering stiffness.

In Figure 6 is depicted the time course of lateral acceleration of automobile, but for the non-linear side slip characteristics, defined by the Pacejka's Magic Formula - Equation (7). As can be seen, this description of the dependence between the lateral force and side slip angle results in better adjustment of the simulation in comparison to the measurement.

To conclude about the differences between simulation and measurement results of lateral acceleration, the following Equation (8) was used.

$$
D_{i \_a y}=\frac{a_{y s i m \_i}-a_{\text {ymeas } i}}{a_{\text {ymeas } \_}} \cdot 100 \%,
$$

where:

$D_{i \_a y}$ - difference in percentages between the simulated and measured lateral acceleration for i-point of simulation;

$a_{y s i m_{-} i}$ - simulated lateral acceleration for i-point of simulation;

$a_{y m e a s_{-} i}$ - measured lateral acceleration for i-point of simulation.

Then, for 14 seconds of simulation the standard deviation of the difference $D_{i \_a}$ was calculated. It was shown below for two different formulas describing the dependence between lateral force and side slip angle:

- for Equation (6):

$\sigma_{D_{i \_a} a_{y}}=1074 \%$,

- for Equation (7):

$$
\sigma_{D_{i \_a}}=281 \% \text {. }
$$

In analogy to the lateral acceleration, in Figure 7 is depicted the time course of yaw angular velocity of automobile on the background of the yaw velocity recorded from the CAN bus. In the case of the most simplified (linear) dependence between the lateral force and slip angle, values of simulated yaw velocity are a bit too high compared to the measured values. In the case of Figure 8, where for the dependence between the lateral force and a slip angle the Magic Formula was applied, the simulated course of yaw velocity is a bit below the measured values.

Like the comparison of simulated and measured values of lateral acceleration, here are presented the standard deviations of differences calculated for the yaw velocity using Equation (9):

$D_{i \_}=\frac{\dot{\phi}_{\text {sim_i } \_}-\dot{\phi}_{\text {meas } \_i}}{\dot{\phi}_{\text {meas } \_} i} \cdot 100 \%$,

where:

$D_{i \_} \phi$ - difference in percentages between simulated and measured yaw velocity for i-point of simulation;

$\dot{\phi}_{\text {sim_i }}$ - simulated yaw velocity for i-point of simulation, $\dot{\phi}_{\text {meas } \_} i$ - measured yaw velocity for i-point of simulation. 


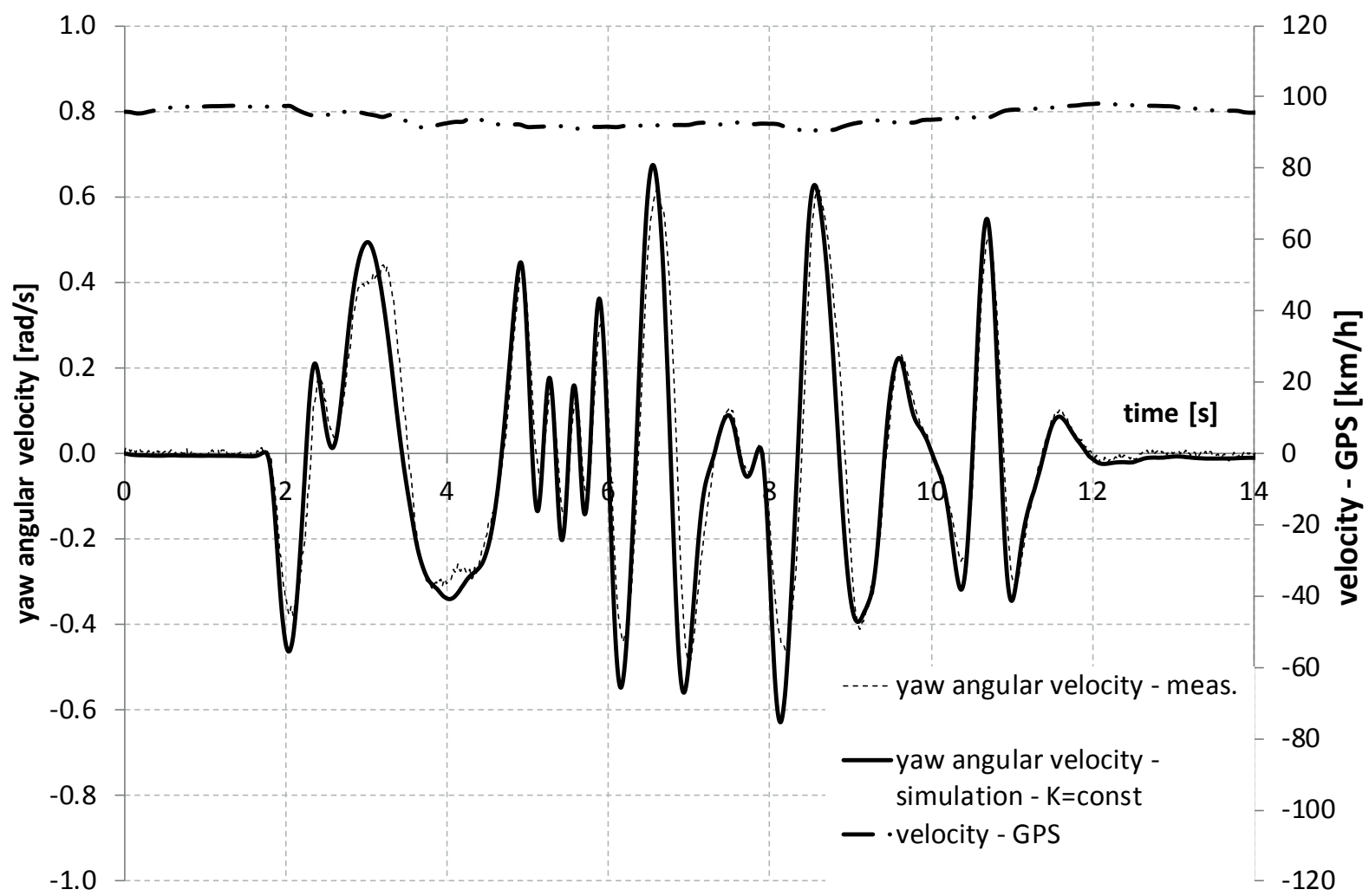

Figure 7 The time course of the yaw angular velocity of investigated vehicle for the linear side slip characteristics

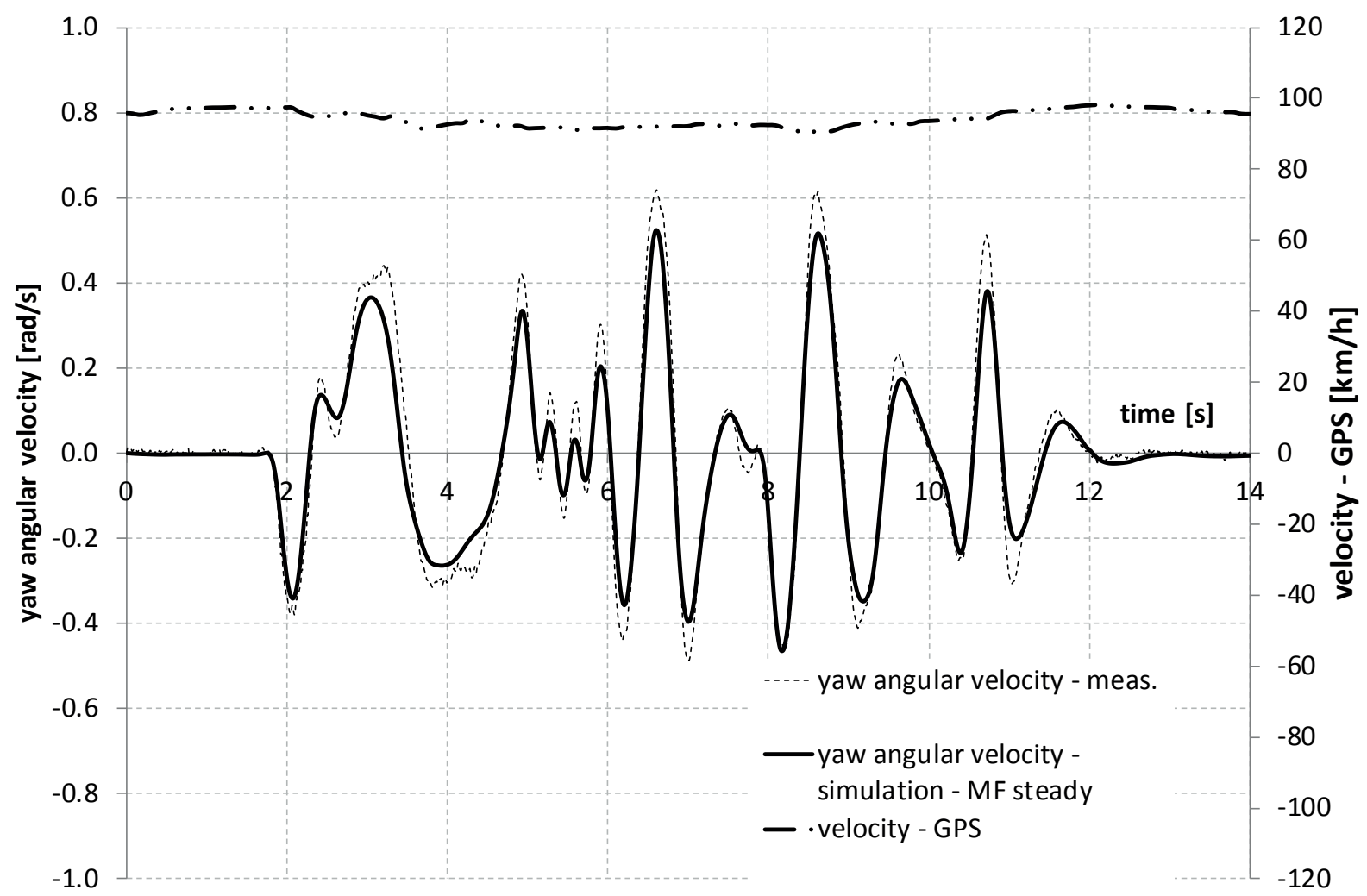

Figure 8 The time course of the yaw angular velocity of investigated vehicle for the side slip characteristics described by Pacejka's Magic Formula 
In analogy to the lateral acceleration, for 14 seconds of simulation the standard deviation of the difference $D_{i \_}$was calculated. It is presented below for the two different equations of dependence between the lateral force and a side slip angle:

- - for Equation (6):

$\sigma_{D_{i-\phi}}=845 \%$,

- $\quad$ - for Equation (7):

$\sigma_{D i \_}=591 \%$.

In the future it is planned to more precisely obtain all the model's parameters with the application of an optimization method like neural networks or random method like Monte Carlo algorithm. Including more DOFs (degrees of freedom) in the motion model would improve the quality of simulation results, but that is planned in the future. In particular, changes of the vertical load of the wheels will be performed in the future works. Moreover, improvement of the model will be possible because of unlocking roll and pitch motion of vehicle's body.

\section{Conclusion}

Application of a simple flat model of vehicle's curvilinear motion requires relatively low number of identified parameters. Such a model was applied in this paper as well as the results of road tests, which came from recording signals typical for electronic stability program (ESP). It was done through the special CAN bus measurement card and own data management-acquisition software made in LabView environment. Presented method of the measurement is not an alternative for dedicated measurement equipment. In the future, the method of collecting data from the CAN bus should be compared to simultaneously recorded signals using the traditional equipment in terms of possible phase shifts between the individual signals from the CAN bus, which is dedicated for information interchange between the electronic modules of a vehicle. However, it is justified to improve the presented method recording the signals, which are important if concerning lateral dynamics' problems of automobiles and automotive safety.

\section{References}

[1] JURECKI, R. Influence of the scenario complexity and the lighting conditions on the driver behaviour in a car-following situation. Archiwum Motoryzacji [online]. 2019, 83(1), p. 151-173 [accessed 2020-07-10]. eISSN 2084-476X. Available from: https://doi.org/10.14669/AM.VOL83.ART11

[2] JURECKI, R., POLIAK, M., JASKIEWICZ, M. Young adult drivers: simulated behaviour in a car-following situation. Promet - Traffic and Transportation [online]. 2017, 29(4), p. 381-390 [accessed 2020-07-10]. ISSN 0353-5320, eISSN 1848-4069. Available from: https://doi.org/10.7307/ptt.v29i4.2305.

[3] JURECKI, R. S., STANCZYK, T. L., JASKIEWICZ, M. J. Driver's reaction time in a simulated, complex road incident. Transport [online]. 2017, 32(1), p. 44-54 [accessed 2020-07-10]. ISSN 1648-4142, eISSN 1648-3480. Available from: https://doi.org/10.3846/16484142.2014.913535

[4] JURECKI, R. S., STANCZYK, T. L. Driver reaction time to lateral entering pedestrian in a simulated crash traffic situation. Transportation Research Part F: Traffic Psychology and Behaviour [online]. 2014, 27, p. 22-36 [accessed 2020-07-10]. ISSN 1369-8478. Available from: https://doi.org/10.1177/107754631247291610.1016/j. trf.2014.08.006

[5] MAKOWSKI, M., KNAP, L. Reduction of wheel force variations with magnetorheological devices. Journal of Vibration and Control [online]. 2014, 20(10), p. 1552-1564 [accessed 2020-07-10]. ISSN 1077-5463, eISSN 1741-2986. Available from: https://doi.org/10.1177/1077546312472916

[6] MAKOWSKI, M., ZALEWSKI, R. Vibration analysis for vehicle with vacuum packed particles suspension. Journal of Theoretical and Applied Mechanics [online]. 2015, 53(1), p. 109-117 [accessed 2020-07-10]. ISSN 1429-2955, eISSN 2543-6309. Available from: https://doi.org/10.15632/jtam-pl.53.1.109

[7] LOZIA, Z. Rollover thresholds of the biaxial truck during motion on an even road. Vehicle System Dynamics [online]. 1998, 29(sup1), p. 735-740 [accessed 2020-07-10]. ISSN 0042-3114, eISSN 1744-5159. Available from: https://doi.org/10.1080/00423119808969601

[8] YU, X., HUANG, H., ZHANG, T. A theoretical three-dimensional ring based model for tire high-order bending vibration. Journal of Sound and Vibration [online]. 2019, 459, p. 114820 [accessed 2020-07-10]. ISSN 0022-460X. Available from: https://doi.org/10.1016/j.jsv.2019.06.027

[9] HAVAJ, P., The quality and the complete evidence securing during the traffic crime scene investigation and its relevance for evidence completion during the traffic accidents. Communications - Scientific letters of the University of Zilina [online]. 2018, 20(4), p. 76-81 [accessed 2020-07-10]. ISSN 1335-4205, eISSN 2585-7878. Available from: https://doi.org/10.26552/com.C.2018.4.76-81

[10] LOKTEV, D. A., LOKTEV, A. A., SALNIKOVA, A. V., SHAFOROSTOVA, A. A. Determination of the dynamic vehicle model parameters by means of computer vision. Communications - Scientific letters of the University of Zilina [online]. 2019, 21(3), p. 28-34 [accessed 2020-07-10]. ISSN 1335-4205, eISSN 2585-7878. Available from: https://doi.org/10.26552/com.C.2019.3.28-34 
[11] SUDRYCHOVA, I., KUCZAJ, J., JANOSIK, L., POLEDNAK, P., JANOSIKOVA, I. Firefighting vehicles braking distance metering. Communications - Scientific letters of the University of Zilina [online]. 2019, 21(3), p. 85-91 [accessed 2020-07-10]. ISSN 1335-4205, eISSN 2585-7878. Available from: https://oi.org/10.26552/ com.C.2019.3.85-91

[12] XUE, K., NAGAYAMA, T., ZHAO, B. Road profile estimation and half-car model identification through the automated processing of smartphone data. Mechanical Systems and Signal Processing [online]. 2020, 142, 106722 [accessed 2020-07-10]. ISSN 0888-3270. Available from: https://doi.org/10.1016/j.ymssp.2020.106722

[13] Bluetooth GPS Receiver [online] [accessed 2020-07-10]. Available from: http://www.qstarz.com/Products/GPS\%20 Products/BT-Q818XT-F.htm

[14] USB-8502 - CAN Interface Device [online] [accessed 2020-07-10]. Available from: https://www.ni.com/pl-pl/ support/model.usb-8502.html

[15] BURG, H. Approximation of moments of inertia in passenger cars / Approximation von Tragheitsmomenten bei Personenkraftwagen (in German). Der Verkehrsunfall. 1982, 20, p. 61-63. ISSN 0341-2210.

[16] PACEJKA, H. B. Tire and vehicle dynamics. Elsevier, 2012. ISBN 9780080970165, eISBN 9780080970172. 